\title{
Prescription Pattern In Hypertensive Patients In A Tertiary Care Teaching Hospital, Dhaka, Bangladesh
}

\author{
Roy US ${ }^{1}$, Khandaker NR ${ }^{2}$, Uddin $\mathrm{S}^{3}$, Khan $\mathrm{MR}^{4}$, Sarker NR
}

Conflict of Interest: None Received: 13 August 2016 Accepted: 22 November 2016 www.banglajol.info/index.php/JSSMC

\section{Key Words:}

Drug Utilization; Rational

Prescribing; Fixed Dose

Combinations; Therapeutic Audit; Hypertensive Patients.

\begin{abstract}
Background: Irrational drug prescribing is a common practice globally; it results in increased morbidity, mortality \& economic burden on society. Drug utilization studies are an important tool to promote rational prescribing.
\end{abstract}

Aims \& Objective: To study on drug prescribing pattern in hypertensive patients.

Materials and Methods: A drug utilization study was conducted in hypertensive patients by the department of cardiology in OPD at Shaheed Suhrawardy Medical college hospital for 6 months. 645 prescriptions were evaluated for prescribing pattern by using WHO drug use indicators.

Results: 645 prescriptions were analyzed. A total of 1828 drugs were prescribed. 697 (38.13\%) antihypertensive, 243 (13.30\%) anti diabetics, 174 (9.52\%) non-steroidal anti-inflammatory drugs (NSAIDs), 154 (8.44\%) statins, 114 (6.24\%) thyroid hormone, 54 (2.95\%) anti-anxiety/ antidepressants and 392(21.44\%) miscellaneous drugs were prescribed. 697 antihypertensive drugs were prescribed. 234 (33.57\%) angiotensin receptor blockers (ARBs), 117 (16.79\%) angiotensin converting enzyme (ACE) inhibitors, 95 (13.63\%) Beta blockers, 83 (11.91\%) Calcium channel blockers 168 (24.10\%) Fixed dose combinations (FDCs) of antihypertensive were included. 2.83 drugs were prescribed per prescription. 225 (32.28\%) antihypertensive were prescribed from essential medicine list.

Conclusion: Most commonly prescribed drugs were ARBs and ACE inhibitors. Rational prescribing requires consideration to dose and duration and interaction with other medications.

Key Words: Drug Utilization; Rational Prescribing; Fixed Dose Combinations; Therapeutic Audit; Hypertensive Patients.

[J Shaheed Suhrawardy Med Coll 2016; 8(2): 39-43] DOI: http://dx.doi.org/10.3329/jssmc.v8i2.37241

\section{Introduction}

Hypertension is one of the major chronic diseases resulting in high mortality and morbidity worldwide. $^{1,2}$ It is a leading risk factor for coronary heart disease, stroke and chronic renal disease. Evidence from large clinical trials now suggests that lowering blood pressure effectively prevents these adverse outcomes. ${ }^{3,4}$ Selection of antihypertensive

1. Dr. Udoy Shankar Roy, Associate professor, Department of Cardiology, Shaheed Suhrawardy Medical College, Dhaka, Bangladesh.

2. Prof. Nazibur Rahman Khandaker, Professor, Department of Cardiology, Shaheed Suhrawardy Medical College, Dhaka, Bangladesh

3. Dr. Saleh Uddin, Assistant professor, Department of Cardiology, Sher- E- Bangla Medical College, Barisal, Bangladesh

4. Dr. Murshidur Rahman Khan, Assistant Professor, Department of Cardiology, Shaheed Suhrawardy Medical College, Dhaka, Bangladesh

5. Dr. Nihar Ranjan Sarker, Associate Professor, Department of Paediatrics, Shaheed Suhrawardy Medical College, Dhaka, Bangladesh

Correspondence: Dr. Murshidur Rahman Khan, Assistant Professor, Department of Cardiology, Shaheed Suhrawardy Medical College, Dhaka, Bangladesh agents should therefore be based primarily on their comparative ability to prevent these complications. It is therefore important that once the diagnosis of hypertension is established, blood pressure should be adequately controlled through regular follow- up, lifestyle modification, exercise and effective antihypertensive drugs. ${ }^{5}$ The study of prescribing pattern is a component of medical audit which seeks monitoring, evaluation and necessary modifications in the prescribing practices of the prescribers to achieve rational and cost effective medical care. ${ }^{5}$ It is necessary to define prescribing pattern and to identify the irrational prescribing habits to drive a remedial message to the prescribers. Therefore, drug utilization studies, which evaluate and analyze the medical, social and economic outcomes of the drug therapy, are more meaningful and observe the prescribing attitude of physicians with the aim to provide drugs rationally. 6,7 
Keeping all these facts in consideration, the present study was designed to analyze the prescribing patterns of antihypertensive drugs in a tertiary care teaching hospital in Dhaka, Bangladesh.

\section{Materials and Methods}

A prospective drug utilization study was conducted in hypertensive patients in the Department of Cardiology OPD at Shaheed Suhrawardy medical college hospital for a period of 1st July 2015 to 30th June 2016. Approval of the Institutional Ethics Committee was obtained prior to the commencement of the study. A total of 645 prescriptions were analysed to evaluate the prescribing pattern in hypertensive patients. Prescriptions were assessed using WHO drug indicators like drug class, dosage form, fixed dose combinations (FDCs) and drugs from National Essential Medicine List 2011.

Frequency of utilization of antihypertensive medications was charted. Antihypertensive medications were grouped in 4 major categories: Angiotensin Converting Enzyme (ACE) inhibitors, Angiotensin receptor blockers (ARBs), Calcium channel blockers and Beta blockers. The fixed dose combinations of antihypertensive drugs were also assessed. The antihypertensives prescribed from Essential Medicine List were also assessed. Besides antihypertensives, we evaluated the use of other medications too like antidiabetics, statins, NSAIDS, thyroid hormones, anti-anxiety/antidepressant drugs and other drugs.

\section{Results}

\section{Demographic Profile}

During the entire study period, a total of 645 prescriptions were assessed. 291 (45.12\%) were male and 354 (54.88\%) were female patients. The mean age of patients was 54.14 \pm 1.09 years. The average Body Mass Index (BMI) was $26.22 \pm 0.86 \mathrm{~kg} / \mathrm{m} 2$. The values were expressed in Mean \pm SEM. Majority of patients belonged to middle socio 19(2.94\%) patients belonged to upper socioeconomic status. Family history of hypertension was present in $226(35.03 \%)$ patients. History of addiction to either smoking or alcohol was present in 131 (20.31\%). Comorbid conditions associated with Hypertension included Type 2 Diabetes mellitus in 174 (26.97\%), hypothyroidism in 114(17.67\%), Coronary artery disease in $18(2.79 \%)$ and Bronchial Asthma in $14(2.17 \%)$ patients (Table-I).

\section{Table-I}

\begin{tabular}{|c|c|c|}
\hline \multicolumn{3}{|c|}{ Demographic Profile } \\
\hline \multicolumn{2}{|l|}{ Parameters } & No. $(\%)$ \\
\hline \multicolumn{2}{|l|}{ Females } & $354(54.88)$ \\
\hline \multicolumn{2}{|l|}{ Males } & $291(45.12)$ \\
\hline \multicolumn{2}{|c|}{ Mean Age (years) } & $54.14 \pm 1.09$ \\
\hline \multicolumn{2}{|c|}{$\operatorname{BMI}(\mathrm{kg} / \mathrm{m} 2)$} & $26.22 \pm 0.86$ \\
\hline \multicolumn{2}{|l|}{ Middle SES } & $533(82.64)$ \\
\hline \multicolumn{2}{|l|}{ ower SES } & $93(14.41)$ \\
\hline \multicolumn{2}{|l|}{ Upper SES } & $19(2.94)$ \\
\hline \multicolumn{2}{|c|}{ Family History of HTN } & $226(35.03)$ \\
\hline \multicolumn{2}{|c|}{$\mathrm{H} / \mathrm{O}$ addiction smoking or alcohol } & $131(20.31)$ \\
\hline \multirow{4}{*}{$\begin{array}{l}\text { Coexisting } \\
\text { Conditions }\end{array}$} & Type 2 Diabetes mellitus & $174(26.98)$ \\
\hline & Hypothyroidism & $114(17.67)$ \\
\hline & Coronary Artery disease & $18(2.79)$ \\
\hline & Bronchial Asthma & $14(2.17)$ \\
\hline
\end{tabular}

A total of 1828 drugs were prescribed. 697 (38.13\%) were antihypertensives, $243(13.30 \%)$ antidiabetic drugs, 174 (9.52\%) NSAIDs, 154 (8.44\%) Statins, 114 (6.24\%) Thyroid hormones, $54(2.95 \%)$ anti-anxiety/ antidepressants and miscellaneous category included 392 (21.44\%) drugs (Table II, Figure 1). The miscellaneous category of drugs comprised of multivitamins and antioxidants, antacids, calcium.

Table-II

Different drug class prescribed over the st udy period

\begin{tabular}{ll} 
Drug Class & No. $(\%)$ \\
\hline Antihypertensives & $697(38.13)$ \\
Antidiabetics & $243(13.30)$ \\
NSAIDs & $174(9.52)$ \\
Statins & $154(8.44)$ \\
Thyroid Hormones & $114(6.24)$ \\
Antianxiety/ antidepressants & $54(2.95)$ \\
Miscellaneous & $392(21.44)$ \\
\hline
\end{tabular}

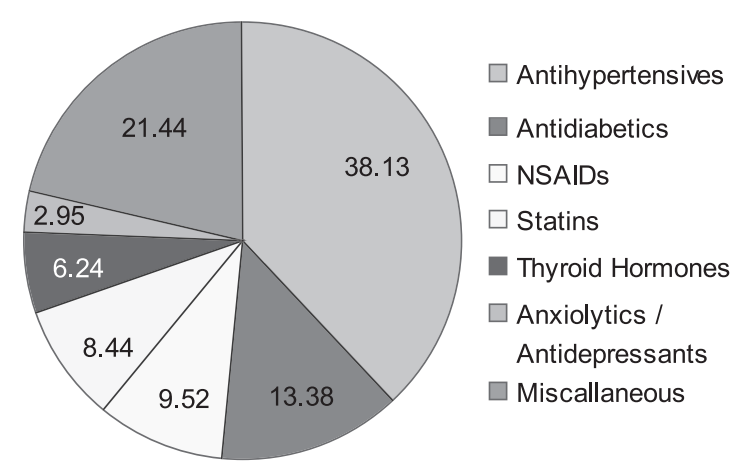

Fig.-1: Different drug class prescribed over the study period 


\section{Antihypertensive Drugs Prescribed}

A total of 697 antihypertensive drugs were prescribed. Angiotensin Receptor blockers (ARBs) were 234 (33.57\%), ACE inhibitors were 117 (16.79\%). Beta blockers were 95 (13.63\%) and Ca channel blockers were 83 (11.91\%).

Total 168 (24.10\%) FDCs were prescribed (Table-III, Figure 2). Amongst ARBs, the leading drugs were Olmesartan 196 (28.12\%), Losartan 20 (2.86\%) and Telmisartan 18 (2.58\%). Amongst ACE inhibitors the most commonly prescribed drug was Ramipril 84 (12.05\%) followed by Enalapril 33 (4.73\%). Atenolol 82 (11.76\%) was the most commonly prescribed Beta blocker followed by Metoprolol 7 (1.04\%) and Nebivolol 6 (0.86\%). Amlodipine $83(11.90 \%)$ was the only Calcium channel blocker prescribed.

\section{Table-III}

Total antihypertensives prescribed

\begin{tabular}{lc} 
Antihypertensives & No. $(\%)$ \\
\hline Angiotensin Receptor Blockers & $234(33.57)$ \\
ACE inhibitors & $117(16.79)$ \\
Beta blockers & $95(13.63)$ \\
Ca channel blockers (CCBs) & $83(11.91)$ \\
Fixed dose combinations & $168(24.10)$ \\
\hline
\end{tabular}

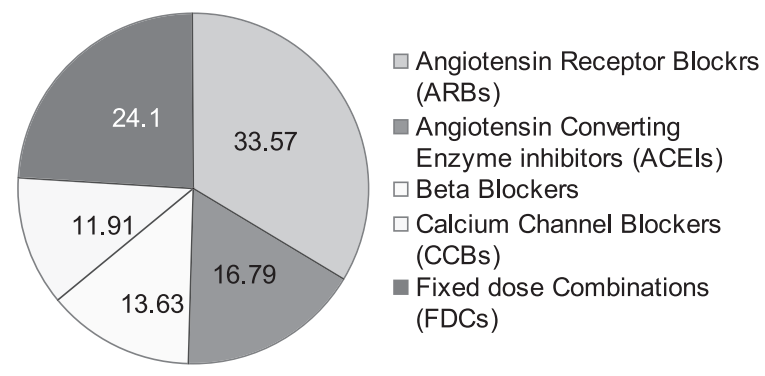

Fig.-2: Total Antihypertensives Prescribed

Out of 168 fixed dose combinations, most common was Two drug combination of Amlodipine and Atenolol 56 (33.33\%) followed by Olmesartan and Hydrochlorthiazide 37 (22.02\%), Losartan and Hydro-chlorthiazide 22 (13.09\%), Ramipril Hydrochlorthiazide 20 (11.90\%), Telmisartan Hydrochlorthiazide 18 (10.71\%) followed by Three drug combination of Olmesartan, Amlodipine and Hydrochlorthiazide 15 (8.9\%). Overall, two drug therapy was more common $153(91.07 \%)$ than three drug therapy $15(8.93 \%)$ (Table IV \& V).
Table-IV

Frequency of administration of individual drugs

\begin{tabular}{llc} 
Drug Class & Drug & No. $(\%)$ \\
\hline Angiotensin receptor & Olmesartan & $196(28.12)$ \\
blockers & Losartan & $20(2.86)$ \\
& Telmisartan & $18(2.58)$ \\
& Total & $234(33.57)$ \\
ACE inhibitors & Ramipril & $84(12.05)$ \\
& Enalapril & $33(4.73)$ \\
Beta blockers & Total & $117(16.79)$ \\
& Atenolol & $82(11.76)$ \\
& Metoprolol & $7(1.04)$ \\
& Nebivolol & $6(0.86)$ \\
& Total & $95(13.63)$ \\
& Ca channel blockers & $83(11.90)$ \\
& Amlodipine & \\
\hline
\end{tabular}

Table-V

Fixed drug combinations

\begin{tabular}{lc} 
Combination drugs & No. $(\%)$ \\
\hline Amlodipine + Atenolol & $56(33.33)$ \\
Olmesartan + Hydrochlorthiazid & $37(22.02)$ \\
Losartan + Hydrochlorthiazide & $22(13.09)$ \\
Ramipril + Hydrochlorthiazide & $20(11.90)$ \\
Telmisartan + Hydrochlorthiazide & $18(10.71)$ \\
Olmesartan + Amlodipine + Hydrochlorthiazide & $15(8.9)$ \\
\hline
\end{tabular}

The average number of drugs prescribed per prescription was 2.83. 97.43\% drugs were prescribed by oral formulations and $100 \%$ drugs were prescribed by their brand names. Out of 697 prescribed antihypertensives, $225(32.28 \%)$ drugs were prescribed from National Essential Medicine List 2011 which included 83 (36.88\%) Amlodipine, 82 (36.44\%) Atenolol, 33 (14.66\%) Enalapril, 20 (8.88\%) Losartan and 7 (3.11\%) Metoprolol (Table-VI).

\section{Table-VI}

\begin{tabular}{lc}
$\begin{array}{l}\text { Antihypertensives prescribed from national essential } \\
\text { Medicine List } 2011 \\
\text { Drugs }\end{array}$ \\
\hline Amlodipine & No. $(\%)$ \\
Atenolol & $83(36.88)$ \\
Enalapril & $82(36.44)$ \\
Losartan & $33(14.66)$ \\
Metoprolol & $20(8.88)$ \\
\hline
\end{tabular}




\section{Discussion}

A prescription based survey is considered to be one of the most effective methods to assess and evaluate the prescribing attitude of the physicians and dispensing practice of pharmacists. It is also important to consider the recommendations of international bodies on hypertension that help to improve prescribing practice of the physicians and ultimately, the clinical standards. A continuous supervision is therefore required through such kinds of systematic audit, which provide feedback from the physician and help to promote rational use of drugs. ${ }^{9}$

The present study observed that incidence of hypertension was higher in females, that was not comparable to the earlier studies on hypertensive patients. ${ }^{10,11}$ The average age of patients in the present study was $54.14 \pm 1.09$ years, reflecting usual age group of disease manifestation. This was comparable to the age of patients in two studies where it was reported to be 52.3 years and 52.93 years. ${ }^{12,13}$ A positive family history was present in 226 (35.03\%) patients in this study. This was comparable with previous study conducted by Rahim MA et al. ${ }^{14}$

Because of the probable multifactorial inheritance, familial association in hypertension has not been proven yet, but there are epidemiological evidences, the association of hypertension with positive family history cannot be undermined. Hypertension is commonly associated with obesity in developed nations, although in developing countries majority of patients were non-obese. BMI of the patients were slight higher $(26.22 \pm 0.86 \mathrm{~kg} / \mathrm{m})$ and not comparable with previous study by Radhika G, Sathya RM et al. ${ }^{15}$ The pattern of hypertension might be changing in our country due the change in life style and food habits. ${ }^{16}$

In the present study it was observed that most commonly prescribed antihypertensive agents were Angiotensin Receptor Blockers and Angiotensin Converting Enzyme Inhibitors, which was comparable with a previous studyby Elliott WJ et al. ${ }^{17}$ The coexisting diseases were diabetes, coronary artery disease and hypothyroidism, and coprescribed drugs were antidiabetics, statins, and thyroid hormones. Since most prevalent coexisting disease was Type 2 Diabetes mellitus, the prescription of ARBs and ACE inhibitors seems justified as these drugs have a protective role in diabetic patients. Previous reports from studies in both humans and animals have revealed that inhibitors of renin angiotensin system have reduced the incidence of new onset diabetes in hypertensive subjects apart from the adequate blood pressure control. ${ }^{17}$ These drugs are known to decrease the onset and progress of microvascular complication of hypertension and diabetes mellitus as described in previous studies. ${ }^{18}$ In the present study diuretics were not used in monotherapy. They were only a party of two/three drug regimen. Under utilisation of diuretics has been reported from time to time. A study by Preethi G Pai et al. has described the decrease in prescribing trend of diuretics. ${ }^{19}$ Lesser use of diuretics in the present study may be due to adverse effects of diuretics on glucose homeostasis and lipid profile. ${ }^{20}$

Earlier studies also suggested that an ideal combination therapy must include antihypertensive drugs possessing complementary modes of action that possess synergistic anti-hypertensive effects without any adverse effects, at low doses. ${ }^{9}$ Furthermore, the antihypertensive drug combination therapy should be able to minimize or counteract the reflex compensatory mechanism that limit the fall in blood pressure. ${ }^{21}$ In the present study two drug therapy was more commonly prescribed than three drug therapy which was comparable with other study. In the two drug combination, a beta blocker (Atenolol) with calcium channel blocker (Amlodipine) was most often prescribed which was comparable with other study by $\mathrm{H}$ Tiwari et al. ${ }^{9}$

In this form of combination and in addition to its favorable complementary synergistic effects, beta blockers tend to blunt the troublesome reflex tachycardia induced by dihydropyridine class of calcium channel blockers. The latter may additionally counteract any peripheral vasoconstriction caused by former. Their combined efficacy has been confirmed in another study without causing adverse drug interactions or poor tolerability. ${ }^{22}$ The fixed dose combination of beta blocker and calcium channel blocker provides efficiency and tolerability in the treatment of arterial hypertension. ${ }^{23}$

Overall, $24.10 \%$ patients in our study received fixed dose combinations. This may be an attempt to improve patient compliance and reduce treatment costs. Such trend of FDCs in hypertension has also been reported in some other studies in India. ${ }^{24}$

Average number of drugs prescribed per patient was 2.83 which was less compared to previous study where 3.97 drugs were prescribed per prescription. In our study all drugs were prescribed by their brand names, poor prescribing of generic drugs can be because of concern about their quality. In the present study 225 (32.28\%) drugs were prescribed from Essential Medicine List which was less as compared with previous study by R Shankar et al where $45 \%$ were prescribed from the National essential medicine list $2011 .^{26}$ 


\section{Conclusion}

To conclude, most of the prescriptions were rational, but further improvement is needed. Further studies focussed on rationale for choice of drug based on demographic data, economic status, associated conditions and complications would give additional insights into prescribing patterns in hypertension in India. Rational prescribing requires consideration to dose and duration as well as interaction with other medications. A therapeutic audit with more parameters of analysis to provide regular feedback to researchers and prescribers may encourage rational prescribing in hypertension.

\section{References}

1. Collins R, Peto R, MacMahon S, Hebert P, Fiebach NH, Eberlein KA, et al. Blood pressure, stroke and coronary heart disease. Shortterm reductions in blood pressure: overview of randomized drug trial in their epidemiological context. Lancet 1990;335:827-38.

2. Hansson L. The benefits of lowering elevated blood pressure: a critical review of studies of cardiovascular morbidity and mortality in hypertension. J Hypertens 1996;14:537-44.

3. Blood Pressure Lowering Treatment Trials Collaboration. Effects of ACE inhibitors, calcium antagonists, and other blood-pressure lowering drugs: results of prospectively designed overviews of randomized trials. Lancet 2000;355:1955-64.

4. Staessen JA, Wang JG, Thijs L. Cardiovascular protection and blood pressure reduction: a meta-analysis. Lancet 2001;358:1305-15.

5. Gupta N, Sharma D, Garg SK, Bhargava VK. Auditing of prescriptions to study utilization of antimicrobials in tertiary hospital. Indian J Pharmacol 1997;29:411-5.

6. Kapoor B, Raina RK, Kapoor S. Drug prescribing pattern in a teaching hospital. Ind J Pharmacol 1985;17:168.

7. Pradhan SC, Shewade DG, Shashindran CH, Bapna JS. Drug utilization studies. National Med J India 1988;1:185.

8. Yuen YH, Chang S, Chong CK, Lee SC, Critchlev JA, Chan JC. Drug utilization in a hospital general medical outpatient clinic with particular reference to antihypertensive and antidiabetic drugs. J Clin Pharm Ther 1998;23:287-94.

9. Tiwari H, Kumar A, Kulkarni SK. Prescription monitoring of antihypertensive drug utilization at the Panjab University Health

10. Centre in India. Singapore Med J 2004;45:117-20.

11. Burt VL, Whelton P, Roccella EJ, Brown C, Cutler JA, Higgins $\mathrm{M}$, et al. Prevalence of Hypertension in the US adult population. Hypertension 1995;25:305-13.

12. Zachariah MG, Thankappan KR, Alex SC Sarma PS, Vasan RS. Prevalence, correlates, awareness, treatment and control of hypertension in a middle aged urban population in Kerela. Indian Heart J 2003;55:245-51.

13. Shobha JC, Kumar TR, Raju BS, Kamath S, Rao M, Harwal, et al. Evaluation of efficacy and safety of Losartan potassium in the treatment of mild to moderate hypertension as compared to Enalapril maleate. J Assoc Physicians Ind 2000;48:497-500.

14. Fogari R, Zoppi A. Comparative effects of Lisinopril and Losartan on insulin sensitivity in the treatment of non diabetic hypertensive patients. Br J Clin Pharmacol 1998;46: 467-71.

15. Rahim MA, Rahman MM, Rahman M, Ahmed F, Chowdhury J, Islam F. The Prevalence rate of Hypertension in Rural Population of Bangladesh 2012;18:12-7.

16. Radhika G, Sathya RM, Sudha V, Ganesan A, Mohan V. Dietary salt intake and hypertension in an urban south Indian population [CURES-53]. J Assoc Physicians Ind 2007;55:405-11.

17. Mqonda YM, Ramaiya KL, Swai AB, McLarty DG, Alberti KG. Insulin resistance and hypertension in non-obese Africans in Tanzyania. Hypertension 1998;31:114-8.

8. Elliott WJ, Meyer PM. Incident diabetes in clinical trials of antihypertensive drugs: a network metanalysis. Lancet 2007;369:201-7.

19. European Society of Hypertension-European Society of Cardiology Guidelines Committee. J Hypertens 2003;21(6):1011-53.

20. Pai PG, Shenoy J, Sanji N. Prescribing Patterns of antihypertensives drugs in a south Indian tertiary care hospital. Drug Invention Today 2011;3:38-40.

21. Prisant LM, Beall SP, Nicholads GE, Feldman EB, Carr AA, Feldman DS, et al. Biochemical, endocrine, and mineral effects of indapamide in black women. J Clin Pharmacol 1990;30:121-6.

22. Chalmers J. The place of combination therapy in the treatment of hypertension in 1993. Clin Exp Hypertens 1993;15:1299-313.

23. Dahlof B, Hosie J. Antihypertensive efficacy and tolerability of a fixed combination of metoprolol and felodipine in comparison with the individual substances in monotherapy. The Swedish/United Kingdom Study Group. J Cardiovasc Pharmacol 1990;16:910-6.

24. Carre A. Pharmacologic importance of the combination atenolol/nifedipine in hypertensive patients. Drugs 1998;56 Suppl 2:23-30.

25. Augustine L, Prasanth NV, Sanal Dev KT, Jasmin S, Kappekkat Y, Shinu C, et al. A study conducted on prescribing pattern and cost of anti-hypertensive drugs in a tertiary level hospital in South Malabar region of Kerala. Der Pharma Chemica 2010;2(6):332-41.

26. Mirza B, Shaktibala D, Amit V, et al. A study of drug prescribing pattern in hypertensive patients in a tertiary care teaching hospital at Dehradhun, Uttarakhand. International Journal of Medical Sciences and Public Health 2014: 3(8):925-930.

27. Shankar R, Partha P, Shenoy N. Prescribing Patterns Of Drugs Among Patients Admitted With Cardiovascular Disorders In The Internal Medicine Ward.: Prescribing Patterns In Inpatients. The Internet Journal of Pharmacology 2001;1:256-68. 